\title{
EL KIKONGO Y SU CONTINUUM \\ EN AFROHISPANOAMÉRICA; POSIBILIDADES ETIMOLÓGICAS PARA SU ESTUDIO
}

\author{
Juan David Luján Villar \\ Universidad Distrital Francisco José de Caldas \\ lujanvillar@gmail.com
}

Recibido: 13/02/2018 - Aceptado: 24/09/2018

doi.org/10.17533/udea.lyl.n75a05

\begin{abstract}
Resumen: Este trabajo aborda el problema de la lengua africana kikongo y su influencia en las hablas afrohispanas. Para esta labor, se realiza una introducción sociohistórica sobre el papel del kikongo en el contexto esclavista del antiguo Reino del Congo, se establece la relación entre este conjunto de dialectos y el habla bozal afroantillana, se realiza un estudio comparativo entre algunas reduplicaciones léxicas y se examina el presunto sustrato subsahariano en el habla bozal a partir de diferentes corpus lexicales. Se concluye que hay un paralelismo morfológico en las reduplicaciones del habla bozal y el kikongo como un presunto aporte africanizante a las lenguas afrohispanas.
\end{abstract}

Palabras clave: kikongo; habla afrohispanoamericana; esclavizados; reduplicaciones; habla bozal.

\section{THE KIKONGO AND ITS CONTINUUM IN AFRO-HISPANIC AMERICA; ETYMOLOGICAL POSSIBILITIES FOR ITS STUDY}

\begin{abstract}
This work addresses the problem of African Kikongo language and its influence on Afro-Hispanic speech. For this work, a sociohistorical introduction is made about the role of Kikongo in the slave context of the former Kingdom of the Congo, establishing the relationship between this set of dialects and Afro-Antillean speech, a comparative study is made between some lexical reduplications and examine the presumed sub-Saharan substratum in Bozal speech from different lexical corpus. We conclude the finding of a morphological parallelism in the reduplications of Bozal speech and Kikongo as a supposed Africanizing contribution to Afro-Hispanic languages.
\end{abstract}

Keywords: Kikongo; Afro-Hispanic American speech; Enslaved; Reduplications; Bozal speech. 


\section{Introducción}

\subsection{Encuentros del español y el kikongo}

Z1 kikongo es un conglomerado de diferentes variantes dialectales o lectos que Cal parecer reúne más de 100 variedades. El grupo étnico gestante de esta lengua es conocido como los bakongo provenientes del antiguo Reino del Congo y la región adyacente de Loango. En el proceso de catequización de los esclavizados en América el kikongo y el kimbundu tuvieron como barrera una primera dificultad, la comunicación a través del idioma. Se presume que muchas de las adaptaciones de los textos de enseñanza de la fe cristiana en el contexto colonial americano de los africanos esclavizados, eran instrucciones que tenían como misión volver inteligible el vocabulario cristiano, a partir de simplificaciones de algunos rasgos lingüísticos del español canónico.

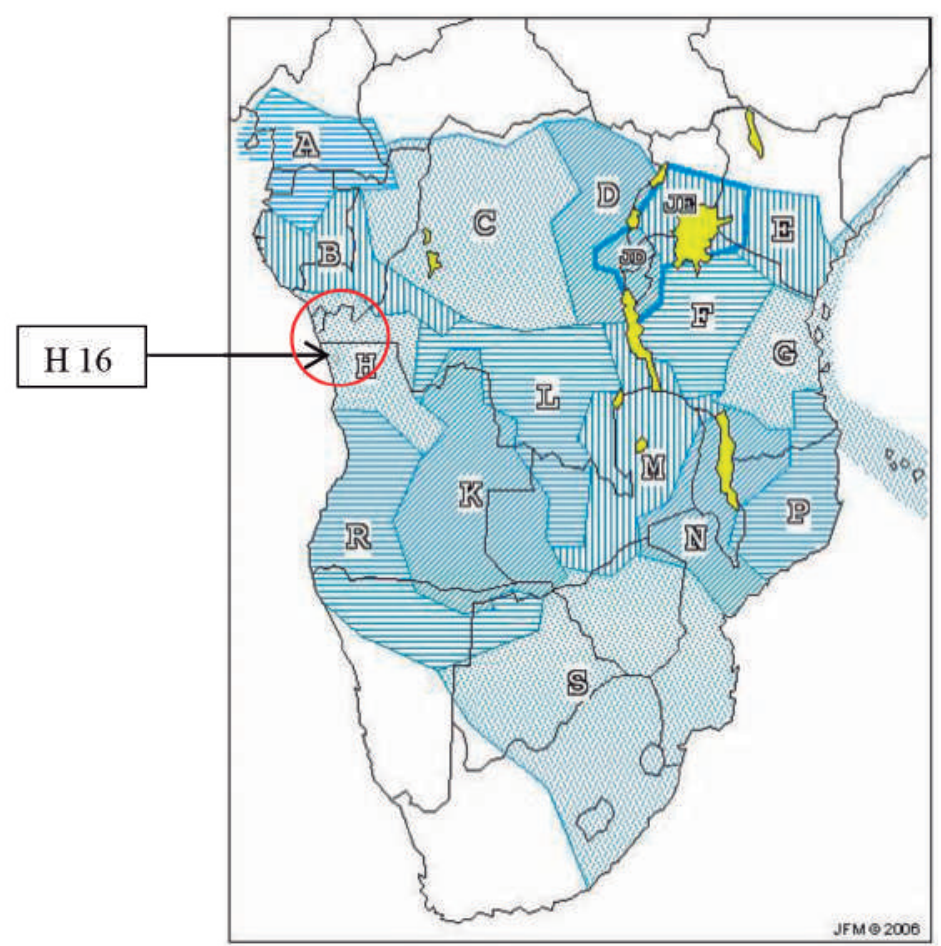

Figura 1. Mapa genético de las lenguas bantúes, la zona del kikongo es clasificada como $\mathrm{H}$ y el subgrupo kikongo figura como H16

Fuente: adaptado de Maho (2006). https://sprak.gu.se/kontakta-oss/doktorander/disputerade-vid-institutionen/ bantu-noun-classes 
Por consiguiente, hazañas interlingüísticas como las descritas anteriormente eran susceptibles de realizarse. A nivel documental encontramos diversas observaciones, en las consideraciones de algunos estudiosos del siglo XVI quienes consideraron la tríada kikongo-kimbundu-español al servicio de las misiones católicas de evangelización, que además, se extendía a los demás romances. Por ejemplo, algunas palabras como quereilla se utilizaba en São Tomé cuando los esclavizados iban de camino a Mina, se dice que llevaban quereillas o sacos en los cuales cargaban comida, el término proviene del < kik. kidila = 'llorón, persona llorosa' (Laman [1936] 1964, p. 650). No obstante, su significado evolucionó y en nuestros días este término designa 'problema o acusación entre dos partes'. Este tipo de relaciones interlingüísticas parecen ser mucho más comunes de lo que parece a primera vista. En el siglo XVI Duarte Lopez consideraba que la relación kikongo-kimbundu-español en términos lingüísticos no era problemática, tal como escribía Filippo Pigafetta (1978) en su Relazione del Reame di Congo original de 1591 (Thornton, 1998, p. 191). Basado en Alonso de Sandoval ([1627] 1956), Thornton (1998, p. 191) especulaba para la zona congolesa cierta homogeneidad cultural y sobre todo lingüística en los pobladores posteriormente esclavizados, lo cual parece corroborarse con datos históricos:

Probablemente fue posible que un hablante de un idioma en la región aprendiera otro sin mucha instrucción especial en aproximadamente tres a cinco semanas, e incluso desde el principio poseían numerosos elementos de vocabulario en común. Del mismo modo, poseían muchos elementos comunes de religión, cánones artísticos y similares.

El corpus lingüístico del kikongo descrito en Occidente data del siglo XVII, y se presume que solo el kimbundu al lado del kikongo fueron documentados por las potencias coloniales que tenían el control de la zona en esta época. Las áreas geográficas que componen el kikongo en los primeros siglos de la trata transatlántica son; Angola (incluyendo Cabinda), Kinshasa (hoy República Democrática del Congo), Brazzaville (actual República del Congo) y Gabón. Por estas razones, se considera que el kikongo constituye un continuo de gran dialecto con estructura de variaciones familiares interdialectales, que evolucionaron de modo diacrónico con el pasar de los siglos (ver Bostoen y de Schryver, 2015).

El padre Mateus Cardoso (natural de Lisboa) quién tradujo en 1624 la Doutrina cristã (...) de novo traduzida na língua do reino do Congo escrita por Marcos Jorge e Ignacio Martinz, llegó a Angola en 1617 (expulsado para Brasil en 1623), testimonió que el kikongo era una lengua muy fácil de aprender, a partir de su experiencia con este idioma en Luanda (Bontinck y Nsasi, 1978, p. 29). Se presume que estas oraciones — sin el catequismo-, fueron impresas por los hermanos de Cardoso en español-kikongo en 
1629. Debido a que Cardoso dedicó la primera traducción de la obra al Rey de Congo, todo indica que este trabajo fue de utilidad en los países de habla castellana para el uso de los jesuitas españoles, quienes practicaban su apostolado con los esclavizados de las posesiones españolas (Bontinck y Nsasi, 1978, pp. 35-36). Algunos historiadores plantean que la relación entre el kimbundu y el kikongo es mucho más cercana de lo que se piensa, puesto que algunos términos devenían etnónimos como Muxicongo $<$ kik. = 'soy del Congo', término que en el campo de la catequización de esclavizados tomó la forma de lengua muxiconga, o Camundongo < kimb. = 'soy habitante de Ndongo', y fueron comunes para designar a los esclavizados provenientes del África Occidental Central según documentación del siglo XIX (Domingues da Silva, 2017, p. 80). Estos datos apoyan una posible monogénesis de la procedencia del habla de los esclavizados africanos y sus derivados afrovernaculares en América. Escribe al respecto Domingues da Silva (2017, p. 85): «Los esclavos kikongo aparecieron por primera vez en el registro histórico a principios del siglo XVI, cuando los comerciantes portugueses zarparon a Angola para comprar esclavos para sus plantaciones de azúcar en Santo Tomé, en la Bahía de Biafra.» Esta circunstancia se establece debido a la centralidad de Luanda como puerto de exportación de esclavizados procedentes de regiones dentro de los 400 kilómetros alrededor de la costa. No obstante, algunos investigadores especializados en Angola consideran la complejidad del origen kikongo como parte de la génesis lingüística de los primeros esclavizados arrancados de territorios africanos, y reconocen con cautela la dificultad de realizar esta comprobación. Según Birmingham (1999, p. 188):

El uso del término "pueblos que hablan Kikongo" puede ser tan anacrónico como la referencia a un imperio del siglo XV. Puede ser que el Kikongo se extendió a las provincias de Kongo como una lengua de comercio durante el siglo XVI. No tenemos evidencia de una manera u otra.

Sin embargo, hoy tenemos evidencia de la expansión del kikongo desde el siglo XVI, pero no la certeza de su papel en el comercio africano. Algunas de las primeras obras que introdujeron el kikongo en la literatura cristiana $-\mathrm{y}$ consideramos que sirvieron como agente de intercambio lingüístico inicial en las relaciones entre el kikongo y el portugués y el kikongo y el español— son las siguientes:

* Gaspar da Conceição, Cartilha da doutrina cristã em lingua do Congo (Évora, 1555).

* Marcos Jorge e Ignacio Martinz, Doutrina christãa (...) De novo traduzida na língoa de Reino de Congo (Lisboa, 1624). Reimpresa como por Mateo Cardoso, Doutrina cristã (...) de novo traduzida na língua do reino do Congo (Lisboa, Geraldo da Vinha, 1624). 
* Mateus Cardoso, Oraciones traducidas en la lengua del Reyno de Angola, por orden del P. Mateo Cardoso Teologo de la Compañía de IESVS, Lima, Geronymo de Contreras (Lima, 1629).

* Giacinto Brusciotto de Vetralla, Doctrina christiana ad profectum missionis totius Regni Congi in quatuor linguas per correlativas columnas distinctas (Roma, 1650).

* Francisco Pacconio, kimbunbu Gentio de Angola sufficientemente instruido nos mysterios de nossa Sancta Fé (Lisboa, 1642).

* Misioneros capuchinos Bonaventura de Sardegna, Diccionario trilingüe quicongo, español, latín (una antigua gramática kikonga, en la actualidad extraviada) (ca. 1649).

* Manuel Roboredo, Doctrina christiana y explicación de sus misterios, en nuestro idioma español, y en lengua arda escrita por el capuchino español José de Nájera (Madrid, 1658).

* Brusciotto de Vetralla, Regulae quaedam pro dificillimi Congiensium idiomatis faciliori captu ad grammaticae normam redactae (Roma, 1659). Algunas reglas para una mejor comprensión de la más dificil lengua del Congo reducidas a las normas de la gramática.

* Pedro Dias, Arte da língua de Angola (Lisboa, 1697) (Bontinck y Nsasi, 1978; Hilton, 1985, pp. 304-305; Borja, 2010, pp. 76-77; Santos Morillo, 2015, p. 76; Zwartjes, 2011, pp. 205-214).

La historia de las enseñanzas de los romances a las poblaciones africanas se remonta por lo menos al siglo XVI, donde los portugueses comerciantes que residían en el antiguo Congo encontraron la necesidad de abrir sus senderos comerciales. Tras la decadencia de la compra y venta de telas en el Congo, la trata esclavista desde Luanda fue inyectada por mandato de Salvador Correia (soldado y político portugués). A partir de esta estrategia, desde mediados de siglo XVII el comercio directamente se fortaleció desde Luanda, debido a la reanudación de las importaciones desde Loango en lugar de Kongo como habían establecido los holandeses tiempo atrás. Este cambio tuvo repercusiones en la difusión del kikongo, debido a que la mayor parte del comercio anterior había sido realizado por residentes portugueses en el Congo. Se sabe que estos personajes hablaban kikongo, tenían esposas congolesas y entendían las complejidades del negocio de la esclavitud humana (Hilton, 1985, pp. 164-165). El cambio sucedió debido a la guerra desatada con la invasión holandesa al Congo, en la cual muchos portugueses murieron (aunque Correia retuvo a Angola y la isla de Santo Tomé de los holandeses). Como afirma Hilton: «A mediados del siglo XVII, los esclavos de Makoko, que tradicionalmente abastecía a Kongo, fueron cada vez 
más llevados al noroeste por comerciantes de Vili a Sonyo y los estados costeros del norte» (1985, p. 165). Por consiguiente, desde 1648 cuando se realizó la última modificación del tratado congo-portugués, se inició la restauración portuguesa y la destrucción paulatina del Reino Unitario del Congo entre 1648 y 1665, aunque los portugueses conocieron el Congo en 1482. Las rutas de comercio poseían diferentes particularidades. Vansina (1962) identifica tres tipos de rutas: 1) un nivel local o aldeano en el cual se realizaban pequeños intercambios de diferentes materias primas como cerámicas o maderas, distribuidos en mercados locales; 2) una segunda forma se constituía en el intercambio entre diferentes espacios geográficos mucho mayores en términos de distancia, a nivel estatal o interétnico, donde existían intercambios de algunos bienes más costosos de lo usual para clases altas basadas en la moda, o igualmente para artículos básicos como la alfarería. Esta ruta tenía conexiones con la estructuras políticas y estatales; y 3) el comercio de larga distancia implantado desde el siglo XV con el arribo de los europeos al continente africano, el cual introdujo el intercambio de productos europeos, como telas, cauris, perlas, armas de fuego, polvo, vino y, en algunos casos, objetos de hierro o cobre para los esclavos, marfil y cobre a fines del siglo XVII, y a fines del siglo XIX cera, caucho, entre otros. Es en ésta última modalidad en la cual se unen algunos reyes africanos y europeos para iniciar desde los puertos costeros, la recepción y envío hacia el resto del mundo de las mercancías africanas. Para esto se debían realizar caravanas desde las ciudades del interior africano: San Salvador, Kassange, Bailundo, Bihe, Kakonda, Loango, Malemba y Kabinda fueron asientos desde los cuales se controlaban los alimentos básicos y la organización comercial.

Respecto al inicio de la esclavitud humana en la fase moderna, fue dirigida por los comerciantes europeos denominados pombeiros, quienes conducían las caravanas hacia Stanley Pool y compraban esclavos (denominados piezas) originarios del Hum, el Teke y los prisioneros de guerra procedentes de países más allá del Reino de Teke, muy al norte o al noroeste de Stanley Pool — ahora llamado Malebo Pool(Vansina, 1962, p. 378). El término pombeiro es de origen kikongo y proviene del termino Mpumb (españolizado como pumbos o mercado de esclavos) el cual es además el nombre nativo de Stanley Pool y Léopoldville, y se aplicó a los esclavistas por lo menos desde 1584. Hilton considera que los descendientes de los pombeiros tuvieron progenie a la cual se le denominó mestiza, y continuó la esclavitud en las diversas colonias creando nuevas rutas de comercio; «sus hijos mulatos formaron una comunidad de comerciantes separada. A principios del siglo XVII, estas colonias de pombeiros se habían establecido junto con las rutas de comercio de esclavos de Kongo» (1985, p. 71). 


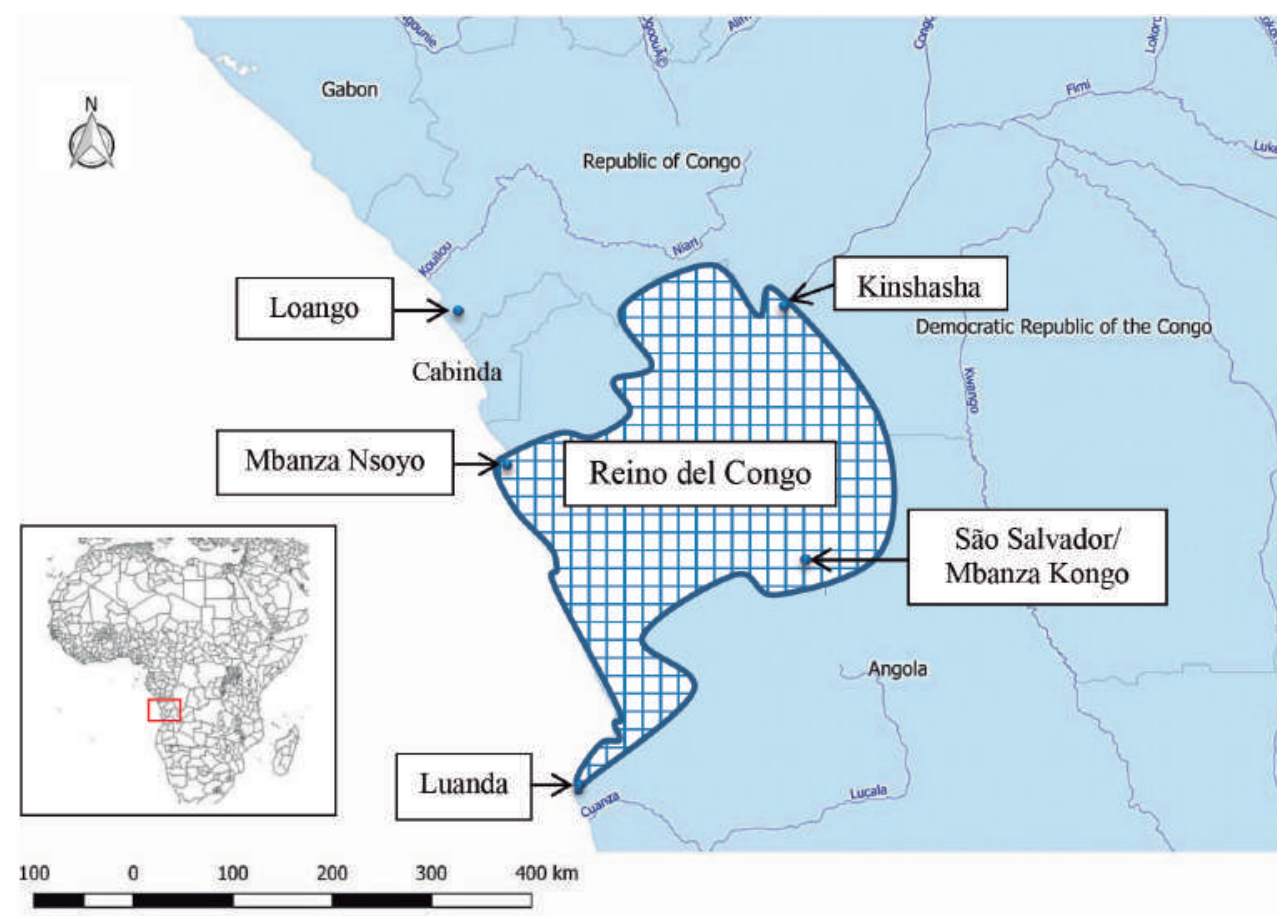

Figura 2. Mapa aproximado del Reino del Congo

Fuente: elaboración propia a partir de Fernando (2008, p. XVI).

La figura 2 ilustra el mapa del antiguo Reino de Congo y demarca la influencia del kikongo antiguo. Este mapeado delinea la influencia de este primer contacto lingüístico entre comerciantes y esclavizados, no solo en términos de asimilación por parte de esclavizados y esclavistas, también de la creación de una posible lengua sostenida entre ambos. Como se puede deducir, uno de los primeros problemas de este contacto inicial fue la comunicación interlingüística. Por consiguiente, es posible pensar en la germinación de este conducto lingüístico afroeuropeo de intercomprensión, el cual podría pensarse arribó a América y continuó con el amalgamiento léxico y estructural de algunos dialectos populares y afrohispánicos. Como hecho paradigmático, esta posibilidad de acercamiento es susceptible de reconocerse en diversos niveles de la lengua bozal (la cual abordaremos más adelante) donde se analizará el rasgo específico de la reduplicación reconocido tanto en la lengua bozal (Perl, 1988) como en el kikongo (Laman ([1936] 1964) y Bentley (1895). 


\begin{tabular}{|c|c|c|c|c|}
\hline Fase & Kikongo & Año & Fuente & Referencia \\
\hline 1 & mutu/mitu & 1624 & Catequismo & (Bontinck y Nsasi, 1978) \\
\hline $1 \rightarrow 2$ & mutu $\rightarrow m^{\prime} t u$ & 1652 & Vocabulario congolés & (Van Gheel, 1652) \\
\hline 2 & $n t u$ & 1714 & $\begin{array}{l}\text { Desde una carta escrita en italiano } \\
\text { en agosto de } 1714 \text {, por el capuchino } \\
\text { Francesco da Troyan (en Congo 1705- } \\
\text { 1714) al Papa Clément XI. [fol. 442] }\end{array}$ & (Jadin, 1961: 584) \\
\hline
\end{tabular}

Tabla 1. Palabra del sur de kikongo para «cabeza (s)»

Fuente: Bostoen y de Schryver (2015, p. 10)

La tabla 1 plantea la evolución de la palabra «cabeza» y sus múltiples fases y giros a través de las centurias, explica la dificultad aún mayor respecto a la investigación de las palabras de origen kikongo aún existentes en Afroamérica, debido a los procesos evolutivos que esta lengua experimentó paulatinamente. Parte de esta dificultad radica en la diferencia que describe Laman ([1936] 1964, p. LX) cuando advierte que los prefijos $b a, b u, b i$ se han convertido en $w a, u, y i$, respectivamente. En este sentido nos encontramos ante un caso de diferenciación dialectal, una forma de innovación fonológica conocida como reducción de prefijos (Bostoen y de Schryver, 2015). Esto significa desde una perspectiva diacrónica que el cambio de lengua ocurrido en América a propósito del caso de las lenguas vernaculares afrohispánicas, se puede comprender como algo relacional a lo ocurrido en África. Paralelo que amplía la idea de una génesis lingüística bastante compleja.

A partir de la estructuración de palabras reconocidas en el acervo afrohispánico y sus unidades mínimas significativas, intentaremos comprender los modos mediante los cuales se posibilita el rastreo coherente de aquellas palabras susceptibles de una indagación lexical. Por ejemplo, los prefijos (en pares, uno que denota singularidad y el otro pluralidad) siempre preceden o se sitúan antepuestos al lexema (ver tablas 3 y 4) o los sufijos que se sitúan pospuestos al lexema. En el contexto del tema que nos ocupa, Fuentes y Schwegler (2014, p. 43) identifican cinco tipos de errores en la caracterización de vocablos de ascendencia africanos -especialmente para el caso de la lengua palera o ritual del Palo Mayombe-:

(a) errores generales de transcripción;

(b) segmentación errónea de las palabras y/o frases; 
(c) traducción mediante asociación contextual;

(d) introducción de voces no africanas en los repertorios (indoamericanismos, cubanismos, anglicismos, onomatopeyas, hipocorismos castellanos, arcaísmos, etcétera);

(e) inclusión de neologismos o palabras «inventadas» por los paleros y algunos -muy pocos- términos en lucumí o ñáñigo (o quien fuere).

Este tipo de advertencias evidencian errores que son usuales no solo en los estudios afrocubanos, ya que el campo de comparación entre África y América implica estos y otros riesgos, también en el plano etnolingüístico. En el devenir del kikongo algunos estudiosos consideran la pérdida de prefijos en sus diferentes variantes. De Kind (2012, p. 200) reflexiona que en kikongo cuando la tensión del sustantivo comienza con una consonante, el prefijo cae, y cuando la raíz comienza con una vocal, el prefijo se retiene. Esta pérdida se puede comprender como un prefijo evolucionado. De esa manera, no podemos olvidar la naturaleza del kikongo basada en una fuerte tradición oral, donde se presume que las variedades del sur del Congo comenzaron su innovación a través de la variación sincrónica que operó desde el antiguo Reino del Congo. Escriben Bostoen y de Schryver (2015, p. 175):

El estatus social que el Kikongo del sur se construyó como lenguaje de la élite y alfabetizado durante el apogeo del Reino, es decir, durante el siglo XVI y principios del XVII indudablemente no dejó de irradiar tan pronto como comenzó el estado central a desintegrarse como consecuencia de una devastadora guerra civil desde finales del siglo XVII en adelante.

A grandes rasgos podemos decir que las variedades del sur se conforman por el kikongo del sur, el kisikongo, el kitsotso, el kizombo y el kisologo (De Kind et al., 2015). No obstante, la génesis de la expansión del kikongo intenta explicar cierto nivel de difuminación de las barreras geográficas en el contexto que nos ocupa, idea difícil de explicar con el detalle que este asunto requiere por términos de espacio. Otra serie de precauciones se presentan desde el siglo XVII, a partir del estudio del diccionario bantú con mayor antigüedad del cual se tenga noticia Vocabularium Latinum, Hispanicum, e Congense original de 1652 desarchivado y actualizado en su momento por el fraile capuchino flamenco Joris van Gheel ([1652] 1896) - cuando realizó su trabajo de misiones en el Congo (actual noroeste de Angola y la parte sur de la provincia del Bajo Congo de la República Democrática del Congo)_- según la adaptación que realizaron del manuscrito original Van Wing, J. y C. Penders en 1928, De Kind, de Schryver y Bostoen (2012) consideran que hay una serie de innovaciones y transiciones realizadas por los capuchinos sobre cambios sustanciales al manuscrito original. Aunque no se sabe con determinación cual es la variedad kikongo en que se basa este ejemplar, De Kind et al. (2012) postulan que se trata de la variante kisikongo hablada en Mbanza Kongo (capital del antiguo 
Reino del Congo), y describen el cambio gramatical kikongo entre los siglos XVII y XX, además del cambio del latín/español al kikongo y del latín/español al francés/ flamenco. También notaron que en este ejercicio el manuscrito original creó algunos neologismos derivados de los lemas del latín/español aplicados a su equivalente en kikongo como consecuencia de no utilizar conceptos congoleses, el uso de paráfrasis y el uso de palabras de préstamo. Procesos que revelan la complejidad lingüística del contexto de la trata transatlántica y las hablas afrohispanoamericanas.

\section{Metodología}

El anterior recorrido histórico sugiere algunas alternativas para la comprensión del continuun kikongo en las hablas afrohispanoaméricas, a partir de las posibilidades etimológicas encontradas para su estudio. El presupuesto metodológico sociolingüístico utilizado es la comparación histórica, dialectal y léxico-semántica del fenómeno conocido como reduplicación, aspecto descrito en diversas investigaciones como un posible rasgo bantú poco fundamental para los romances. Esto sugiere un potencial aporte africano en el habla de estas comunidades (Schwegler, 1990). Por otra parte, el enfoque sociolingüístico histórico de las variedades del español demostró ser útil según varias investigaciones sobre los estudios diacrónicos de la lengua hispánica (Fontanella de Weinberg, 1966).

Para el caso que abordamos nos basamos en los datos presentados por Perl (1988) y Laman ([1936] 1964), el primero es un estudio pionero de la sociolingüística de la lengua bozal y el segundo uno de mayores los referentes mundiales etnográfico y lingüísticos del kikongo. Como complemento utilizaremos los léxicos contenidos en los estudios de Gómez (2010), Schwegler y Rojas-Primus (2010) y Bentley (1895).

Recientemente Schwegler (2016) comprobó a través de datos de la genética de poblaciones y la lingüística histórica que la ancestría africana de los palenqueros de San Basilio en Colombia provenía del noroeste del área de los bakongo (Mayombe y zonas colindantes). A nivel etimológico Fuentes-Guerra y Schwegler (2014) asimismo comprobaron que en el habla ritual conocida como Palo Mayombe en Cuba, la raíz lingüística de la mayor parte de sus elementos africanos proviene del kikongo, agrupado por Malcolm Guthrie (1967-1970) bajo el conglomerado lingüístico H10 (una raíz proto-criolla compartida?) (Ver mapa 1). Este trabajo toma como punto de partida estos descubrimientos lo cual evidencia la pertinencia del enfoque seleccionado. En ambos casos los datos se inclinan hacia la existencia de un sustrato kikongo como parte del origen de ambas lenguas. Paralelo a estos hallazgos, parte de la discusión sustratista y monogenética continúa en discusión en la arena académica y científica (Schwegler, McWhorter y Ströbel, 2016; McWhorter, 2018; Schwegler, 2018; Sessarego, 2017). 


\section{El kikongo y el habla bozal}

En el repertorio del habla bozal afroantillana existen paralelos con las estructuras del kikongo (Lipski, 2007). El habla bozal es la manifestación lingüística de los africanos llegados a América con un dominio incompleto del español. Para algunos expertos existe una suerte de monogénesis en la lengua ritual del Palo Mayombe (Fuentes-Guerra y Schwegler, 2014) -vinculada genéticamente con el habla bozal- encuentra su origen en el kikongo y sus dialectos. El kikongo fue un posible transmisor de diferentes lectos (dialectos/lenguas), esto hace que consideremos su influencia como un sustrato importante en la lengua de los esclavizados en América. Algunas lenguas criollas y pidgins de diferentes bases léxicas o superestratos evidencian elementos kikongo; el calunga (Brasil), el Luango (Suriname), el Púmbu (Suriname), la lengua del Palo Monte Mayombe (Cuba), el Lumbalú (Palenque, Colombia), el habla de los negros Congos de Panamá (Portobelo), el dialecto del Chocó y afropacífico (Colombia), comunidades afroperuanas de la zona de Chincha (Perú), y el dialecto de Barlovento y su habla loango (Venezuela, Estado Miranda) (Byrd, 2012; Correa, 2012; Cuba, 1996; Fuentes-Guerra y Schwegler, 2014; Granda, 1977; Lipski, 1985, 2007; Schwegler, 2014; Smith, 2015).

\begin{tabular}{|c|c|c|}
\hline Glosónimo & Tipo de lenguaje & Autores \\
\hline Calunga (Brasil) & $\begin{array}{l}\text { Secreto/ritual/spiritual [múltiples } \\
\text { elementos bantú principalmente } \\
\text { kikongo, kimbundu y umbundu] }\end{array}$ & $\begin{array}{l}\text { Byrd (2007, 2012a, } \\
2012 b)\end{array}$ \\
\hline Luango [Lángu o Luángu] (Suriname) & Secreto/ritual/spiritual & Smith (2015) \\
\hline Púmbu (Suriname) & Secreto/ritual/spiritual & Smith (2015) \\
\hline Lengua Palo Monte (Cuba) & Secreto/ritual/spiritual & $\begin{array}{l}\text { Fuentes-Guerra } \\
\text { Schwegler (2014) }\end{array}$ \\
\hline Lumbalú (Palenque, Colombia) & Secreto/ritual/spiritual/criollo & Schwegler (2014) \\
\hline $\begin{array}{l}\text { El habla de los negros CONGOS de } \\
\text { (Panamá, Portobelo) }\end{array}$ & Área lingüística & Lipski (1985) \\
\hline $\begin{array}{l}\text { El dialecto del Chocó y afropacífico } \\
\text { (Colombia) }\end{array}$ & Área lingüística & $\begin{array}{l}\text { Granda (1977); Correa } \\
\text { (2012) }\end{array}$ \\
\hline $\begin{array}{l}\text { Comunidades afroperuanas de la zona } \\
\text { de Chincha (Perú) }\end{array}$ & Área lingüística & Cuba (1996) \\
\hline $\begin{array}{l}\text { Dialecto de Barlovento habla Loango } \\
\text { (Venezuela, Estado Miranda) }\end{array}$ & Área lingüística & \\
\hline
\end{tabular}

Tabla 2. Lenguas rituales y hablas afrohispánicas de posible sustrato kikongo

Fuente: elaboración propia a partir de Jacobs (2014, pp. 68-69) y Lipski (2007) 
Respecto a la diáspora kikongo a nivel fonológico algunos investigadores consideran que el cambio de $/ \mathrm{r} />$ [d] puede considerarse como un aporte fonológico del sustrato afrosubsahariano (Lipski, 2007). Este fonetismo fue encontrado en el dialecto del Chocó donde se identificó el cambio $-[r]>[ð]-$ entre otros fenómenos relacionados (Correa, 2012). En el caso del palenquero de San Basilio Schwegler (2016) demostró con amplia profundidad el sustrato lingüístico Kikongo en esta lengua. Todo indica que otros prestamos realizados por el kikongo se encuentran en la asimilación de la /r/ en posición prevocálica, por lo general antes de la /i/: «Eventualmente, la /r/ del portugués fue asimilada al sistema fonotáctico del kikongo», por ejemplo, «María > Madia; Cristo > Kidisitu; América >Medika; farinha $>$ fadina; Henrique > Andiki; servir > sevidila/xidivila (Likangama, 1990, p. 108); separar >sepadala; açucar > nsukadi» (Lipski, 2007, p. 106; Martins, 1958, p. 45). Byrd (2007, p. 209) en el calunga afroportugués de Brasil, notó la reducción de /r/ de manera frecuente; desaprumá(r) [di.za.p(r)u.'ma] o [dzi.za.p( $\Upsilon$ )u.'ma] 'deshacer'; orirá(r) [u.ri.'ra] 'cantar', lo cual se presume es un fenómeno paralelo a la asimilación de la /r/.

Algunos aspectos relacionados sobre préstamos interlingüísticos se perciben en diversos dialectos afrohispánicos, tal como ocurre con el cambio o variación libre que figura en el dialecto del Chocó, por ejemplo, los intercambios de Mosquera $>$ Mosqueda o el cambio de /r/ < [1] carne > calne (Murillo, 2011, p. 32); «espalda $>$ espazda, revuelto $>$ revuerto, palma $>$ parma, balsa $>$ barsa. Casos de cambio $\mathrm{de} / \mathrm{r} />1 /$ son: virgen $>$ vilgen, permiso $>$ pelmiso, recuerdo $>$ arrecueldo, charco $>$ chalco» (Ruiz-García, 2001, p. 133). Esta serie de fenómenos se pueden considerar como remantes de bozalismos, aportes derivados del pidgin afroespañol que caracterizó el habla de los esclavizados afrohispanos en América y el Caribe, lengua conocida como habla bozal. ${ }^{1}$ Gómez (2010) en su trabajo con la comunidad palera de la ciudad de Ciego de Ávila en Cuba, identificó un fenómeno similar entre cambios consonánticos tanto en la linguoalveolar sonora [1] / y la linguoalveolar sonora [r] en palabras de un claro origen kikongo ${ }^{2}$, por ejemplo, eygúlo $\sim$ eygúri $<\mathrm{kik} .=$ 'cerdo' (nótese el cambio vocálico: [o] / [i]) (Gómez, 2010: p. 97), ngóngolo gongoró < kik. = 'animal que vive en las profundidades del cementerio' (Laman, [1936] 1964,

1 Lipski (2006: 2) expone esta perspectiva como una de las rutas posibles para encontrar muestras reales de la antigua habla bozal, junto a otros dos caminos: «(1) la memoria colectiva del habla de los últimos bozales; (2) la supervivencia de elementos bozales en los ritos religiosos y folklóricos afrohispánicos; (3) los vestigios lingüísticos pos-bozales que se encuentran en las comunidades de habla afrolatinoamericanas más aisladas».

2 En kikongo la pronunciación de $n k=[\eta \mathrm{k}], \mathrm{y} n \mathrm{ng}=[\mathrm{yg}]$ y ng' $=[\mathrm{y}]$. Por otra parte Swartenbroeckx (1973) explica que en dialecto kikongo-kituba existen dos tonos alto $(')$ y bajo (`), y un tono de caída $\left({ }^{\wedge}\right)$ el cual ocurre con algunas excepciones al final de la silaba. 
p. 692), ${ }^{3}$ donde se evidencia que durante el cambio consonántico pasa a ser aguda. También se aprecia un fenómeno similar en el cambio consonántico realizado entre la linguodental sonora [d] y la linguoalveolar sonora [r], tal como se puede ver en el término gudunfinda $\sim$ gurufinda $>$ kik. = 'Dios dueño de la vegetación' (Laman, [1936] 1964, p. 693)4 (Gómez, 2010, pp. 64-65-74-82).

En la condición de adyacencia anterior, se evidencia la asimilación consonántica y no solo vocal, lo cual al parecer coincide con otros aspectos del kikongo como el caso del emplazamiento de la /1/ que puede convertirse en [n] cuando le precede en la base una consonante nasal. Por ejemplo, la forma subyacente $/ k u$-kinis-il-al se realiza en $\left[\right.$ kukinisina] < kik. 'hacer bailar para alguien' (Núñez, 2014, p. 148). ${ }^{5}$ Quizá esta sea una característica en la cual el kikongo asimila a través de la condición de adyacencia los intercambios consonánticos explicados. Además podría diferenciarse de una influencia andaluza como se comprobó para el caso de la perdida de la /s-/ al final de la silaba y de palabra, aspecto considerado en el pasado como un rasgo africano (Megeney, 1999). Quizá la prueba definitiva de la manifestación del intercambio $/ \mathrm{r} />$ [d] en apoyo a la hipótesis de Lipski (2007) se encuentre en la explicación que realiza Laman ([1936] 1964, p. XI) cuando expone que el en el bantú (kikongo) del sur, por lo general se reemplaza la $d$ antes de $i$, así tenemos el cambio de $\operatorname{rimb} a>\operatorname{dim} b a([<\mathrm{kik}$. dimba = 'escuchar, escuchar, atento, sing. de la clase 6]), lo cual también aparece en los dialectos kikongo del Occidente; kunyi y teke, entre otros. Debido a que este fenómeno cobra relevancia porque es reconocido en varios dialectos, se infiere un radio de acción grande e influyente.

Es necesario manifestar que no podemos determinar un proceso fonológico de neutralización completo y categórico, mejor se puede comprender como rastros o procesos de memorización afrodiaspórica en el sentido de las conexiones que subsisten desde los procesos coloniales afrohispanos y su relación genética con lenguas de origen bantú. Así, se puede inferir que estas realizaciones pueden llegar a ser estrategias o formas persistentes de un posible sustrato subsahariano. Aunque la base más fuerte de este legado es la comprobación léxico-semántica, los datos demuestran que muchos ejercicios fonológicos - como los ya expuestos- y morfosintácticos, como es el caso de la doble negación evidenciado en el afroespañol de República Dominicana, el dialecto afrochocoano, el palenquero, el afroportugués y el criollo haitiano (Lipski, 2007; Ruiz-García, 2001), reconocido ampliamente en África (Dryer,

3 Laman ([1936] 1964, p. 692) define ngóngolo < kik. = 'ciempiés o miriápodo'.

4 Laman [1936] 1964, p. 39-152-693) define ngúdi < kik. = 'madre', ngùdi < kik. = 'terrón de tierra madre'. En kik. $u$ - es pronombre de la clase 1, mfinda $<$ kik. = 'matorral, selva, (E) arbusto, madera, (SB) bosque'.

5 Laman ([1936] 1964, pp. 262-271) presenta kina, kinisa < kik. = 'bailar'. 
2009), explican las continuidades que los esclavizados y el efecto de su emigración a América sostuvo en el devenir de algunos grupos diferenciados hispanohablantes.

En el Perú colonial está documentado un cántico o poesía emancipadora en «lengua» (¿kikongo?), realizado en honor a José Baquíjano y Carrillo (Lima 1751 - Sevilla 1818), Conde de Vista-Florida, ideólogo y héroe de la revolución peruana, cuando en 1812 fuera promovido al Supremo Consejo de Estado, expresión que quedó registrada y fue retomada por Santa Cruz (1982, p. 70):

Coracónse, ó corangólo

Mepansuambashi.

Baquijano luanda cacáne,

Y fumu ia tulunda

Baquijano cuenda-cacuenda

Nsambi inguá itáta.

Baquijano caníne Congo guaienda

Angui tuina ie fumu

Nguéie utufiri nsala ie moco
Dios te guarde, Dios te guarde fuertemente, Consejero

Baquíjano el hombre grande nos desampara,

El amo que nos defendía

Baquíjano se va, ya se va,

Ya solo Dios nos será madre y padre.

Baquíjano, despídete de los Congos al irte,

Pues aunque tenemos amo,

Tú solo nos dominas hasta las uñas y las manos.

La anterior poesía emancipadora para Lipski (2007, p. 101) es un texto hibrido con elementos lexicales kikongo pero con un fuerte trasfondo post-bozal detrás del cambio $/ \mathrm{r} />$ [d]. Aunque los aspectos kikongo documentados en el Perú no son abundantes en comparación, por ejemplo, con Cuba o Colombia, la composición anterior demuestra la trascendencia interlingüística de una posible lengua vernacular afrohispana consolidado en un determinado momento colonial.

\section{Reduplicaciones bozales y su paralelo kikongo}

En la morfología de las lenguas criollas afrohispanas se encuentra la reduplicación como aspecto lingüístico realizado mediante la duplicación de palabras y morfemas, lo cual en las lenguas bantúes del sur se realiza a través de palabras idiófonos (Childs, 1994). La reduplicación se diferencia de la repetición, en los siguientes sentidos; la primera presenta mayor restricción que la segunda, el número de copias de la repetición puede ser mayor que dos y no se sobrepasa en la reduplicación, la primera puede ser arbitraria o ausente, la segunda es arbitraria o icónica, en la primera puede 
haber más de una palabra pero la segunda es mucho más restringida y presenta una o menos que una palabra (Gil, 2005). Sin embargo, se advierte que la reduplicación puede contener duplicación de segmentos de una palabra o palabras completas.

En la lengua ritual del Palo Monte Mayombe se cuentan cientos de africanismos y en el palenquero se reconocen entre doscientos y trescientos. En ambos casos la mayoría son de un comprobado origen kikongo. Esta realidad establece un marco fiable de comparación, ya que amplía posibilidades investigativas a través de otros aspectos que vinculan el puente entre África y América. El tema de las reduplicaciones es un aspecto que se reconoce en la estructura morfológica de diferentes criollos y pidgins, algunos investigadores tratan de identificar una forma de universalismo en este fenómeno, pero otros estudiosos aseguran que la transmisión de las reduplicaciones depende de cada cultura desde los lenguajes que sirven de base lexical.

Crowley (2008) considera respecto a los criollos que las reduplicaciones léxicas ocurren como un proceso de adaptación entre una lengua lexificadora (o idioma base) y las demás lenguas tributarias (relexificadas). A nivel intralingüístico algunos investigadores sugieren que la replicación puede ser icónica, es decir un cuasi-universal o generalización caracterizada por intensidad, iteración y distribución (Crowley, 2008, p. 87). Kouwenberg y LaCharité (2001, p. 73) en su estudio sobre las reduplicaciones en criollos del Caribe estudian — entre otras lenguas-, el papiamento de base español-portugués y encuentran el sustantivo reduplicado pipita $>=$ 'grano', pipita-pipita $>=$ 'muchos granos', el verbo bula $>=$ 'saltar', bula-bula $>=$ 'para saltar sobre'; kayente $>=$ 'caliente' kayente-kayente $>=$ 'muy caliente'. Dentro de los adjetivos de reduplicación no icónica en papiamento se hallan en la base $z e t a>=$ 'aceite', un significado intensificado zeta-zeta $>=$ 'muy aceitoso'. En el ítem reduplicación no icónica de sustantivos las autoras exponen el verbo base chupa $>=$ 'chupar', y el sustantivo deverbal ${ }^{6}$ de reduplicación $>$ $=$ 'chupar sangre [o chupa sangre]', consideran que esta relación contiene un argumento externo, lo que manifiesta su no iconicidad. En el caso del verbo base tembla $>=$ 'temblar', el sustantivo deverbal de reduplicación tembla-tembla $>=$ 'escalofríos', consideran que la relación es la de un sustantivo abstracto. Crowley (2008) insiste que la función de la reduplicación en la lengua de los criollos no es solo icónica, debido a que también exhibe señales de cambio de palabras y posibles paralelismos estructurales, y del mismo modo — según él-, puede reflejar directamente el sustrato específico.

6 En este contexto Kouwenberg y LaCharité (2001, p. 72) explican que «donde hay un verbo, el adjetivo deverbal atribuye la actividad descrita por el verbo como una propiedad característica, o atribuye una actividad que es similar a la de la base.» Por lo tanto, el sustantivo deverbal o nominalización es un sustantivo derivado de un verbo, por ejemplo, por sufijación de -ción/-miento, -ura/-aje, germinar $\rightarrow$ germinación, estacionar $\rightarrow$ estacionamiento, caricaturizar $\rightarrow$ caricatura, viajar $\rightarrow$ viaje, o por sufijación cero comprar $\rightarrow$ compra . 
Perl (1988) estudió el proceso morfológico de la variante diastrática o sociolecto conocido como habla bozal en Cuba, en el cual el autor asume la existencia de un "continuum poscriollo», es decir, una continuación de los rasgos que fueron criollos en el habla de los esclavizados llegados a Cuba, y tenían como base el portugués, una «lengua universal comercial de la trata de negros de la costa occidental de África» (Perl, 1988, p. 48). Los datos presentados por Perl (1988) identifican las reduplicaciones léxicas como un rasgo bozal quizá de origen africano, aunque el autor no relaciona una raíz kikongo para este fenómeno, nuestro aporte asume esa dirección.

Perl (1988) identifica reduplicaciones de adjetivos y adverbios para el caso de algunas lenguas de África Occidental, en la intensificación de los adjetivos de las palabras idiófonos que realizarían esta función. También se evidencia cierto paralelismo con las reduplicaciones en el criollo jamaiquino y el lenguaje coloquial cubano. En sus datos Perl ejemplifica algunos casos donde ocurren reduplicaciones para intensificar el verbo, fenómeno evidenciado en diversos criollos, e identifica que tales iteraciones son comunes en los criollos de base anglófona -incluyendo el criollo de San Andrés (Colombia) - , aunque Perl considera que el habla bozal manifiesta reduplicaciones — que según el material recaudado por él—contienen ejemplos de las variantes descriollizadas de base ibérica y no-ibérica.

Desde el plano histórico Perl (1988) identifica que algunas de las reduplicaciones proceden del inglés, pero considera que el inglés manifiesto en estos vocablos proviene muy seguramente de un pidgin portugués de la costa occidental de África - un portugués criollo del Golfo de Guinea con lenguas de sustrato como el bini, el kimbundu, el yoruba y el kikongo - notorio en el proceso del tráfico negrero portugués y considerado afrolusitano o afroibérico (Schwegler, 2018), utilizado durante el proceso de la trata esclavista transatlántica, y empleado también por los ingleses. Perl realizó encuestas como mecanismo de comprobación del uso de los términos encontrados, y fueron llevadas a cabo en la región central de Cuba a 60 personas de diferentes condiciones sociales y no solo de poblaciones rurales (Perl, 1988, p. 63). Un estudio complementario realizado por Gómez (2010) sobre el léxico palero cubano complementa nuestra perspectiva del uso de reduplicaciones actuales. Asimismo, el trabajo de Schwegler y Rojas-Primus (2010) presenta algunos ejemplos $\mathrm{y}$ argumentaciones complementarias sobre el tema. Respecto a las posibles etimologías afroportuguesas (p.), hispánicas o habla bozal (hb.), inglesas (i.), lengua palera (lp.), ${ }^{7}$ palenquero (pal.) o kikongo (kik.) de algunas reduplicaciones, encontramos los siguientes paralelismos morfológicos evidenciados en los casos a continuación:

7 Es menester aclarar que la lengua palera clasifica como lengua bozal por razones etnoafricanas compartidas, pero la primera se diferencia de la segunda por su aspecto ritual, donde el habla bozal se realiza mediante momentos de trance, lo cual acentúa su carácter religioso, espiritual y secreto. 


\begin{tabular}{|c|c|c|c|}
\hline Reduplicación & $\begin{array}{c}\text { Etimologías } \\
\text { afrohispánicas }\end{array}$ & Etimología Kikongo & Fuente \\
\hline $\begin{array}{l}\text { cucha-cucha [red. } \\
\text { completa] }\end{array}$ & $<$ hb. $=$ 'escuchar' & $\begin{array}{l}<\text { kik. lu-bīki-biki }>=\text { 'escuchar } \\
\text { con prisa, inesperadamente; } \\
\text { escuchar algo que no es lo } \\
\text { suficientemente claro como para } \\
\text { entenderlo bien' }\end{array}$ & $\begin{array}{l}\text { (Perl, 1988, pp. } \\
\text { 52-63); (Laman, } \\
\text { [1936] 1964, p. } \\
\text { 412) }\end{array}$ \\
\hline $\begin{array}{l}\text { fino-fino [red. } \\
\text { completa] }\end{array}$ & $\begin{array}{l}<\mathrm{hb} .=\text { 'cosa buena, } \\
\text { bien hecha o que se } \\
\text { aprueba' }\end{array}$ & & $\begin{array}{l}\text { (Perl, 1988, pp. } \\
51-63)\end{array}$ \\
\hline $\begin{array}{l}\text { tifi-tifi }^{1}[\text { red. } \\
\text { completa }]\end{array}$ & $\begin{array}{l}<\mathrm{i} .=\text { 'hurtar, robar', } \\
\text { pisi-pisi }\end{array}$ & & (Perl, 1988) \\
\hline $\begin{array}{l}\text { pisi-pisi [red. } \\
\text { completa] }\end{array}$ & $<\mathrm{i} .=$ 'orinar' & & $\begin{array}{l}\text { (Perl, 1988, pp. } \\
\text { 61-63) }\end{array}$ \\
\hline $\begin{array}{l}\text { soqui-soqui [red. } \\
\text { completa] }\end{array}$ & $<\mathrm{i} .=$ 'fornicar' & & (Perl, 1988) \\
\hline $\begin{array}{l}\text { musenga- } \\
\text { musenga [red. } \\
\text { completa] }\end{array}$ & $<$ hb. $=$ 'caña, caña' & $\begin{array}{l}\text { < kik. cēnga = 'caña de azúcar'; } \\
\text { en kik. } m u \text { es prefijo singular de la } \\
\text { clase } 2\end{array}$ & $\begin{array}{l}\text { (Perl, 1988); } \\
\text { (Laman, [1936] } \\
\text { 1964, p. 101) }\end{array}$ \\
\hline $\begin{array}{l}\text { chapi-chapi [red. } \\
\text { completa] }\end{array}$ & $\begin{array}{l}{[<\mathrm{i} . ?] \text { etimología }} \\
\text { no clara podría ser } \\
\text { 'chapear o machetear' }\end{array}$ & $<$ kik. ̀̀koati, ǹkwàti = 'machete' & $\begin{array}{l}\text { (Perl, 1988, pp. } \\
\text { 51-61-63) }\end{array}$ \\
\hline $\begin{array}{l}\text { ñami-ñami [red. } \\
\text { completa] }\end{array}$ & $\begin{array}{l}<\text { hb. }=\text { 'comer o } \\
\text { comida' }\end{array}$ & $\begin{array}{l}<\text { kik. nyáma, nyyama }=\text { 'carne, } \\
\text { comida en general' }\end{array}$ & $\begin{array}{l}\text { (Perl, 1988, pp. 52- } \\
\text { 55-60-63); (Laman, } \\
\text { [1936] 1964, p. } \\
812 \text { ) }\end{array}$ \\
\hline $\begin{array}{l}\text { napi-napi [red. } \\
\text { completa] }\end{array}$ & $<\mathrm{i} .=$ 'dormir' & $\begin{array}{l}<\text { kik. bé }=\text { 'silence, ver pi, napi.', } \\
<\text { kik. pii = 'calma, tranquilidad, } \\
\text { paz'; < kik. = napii = 'tranquilo, } \\
\text { tranquilo; en silencio'; < kik. napi- } \\
\text { pidi-pii = 'silencio profundo' }\end{array}$ & $\begin{array}{l}\text { (Perl, 1988, pp. 52- } \\
60-63) ; \\
\text { (Laman, [1936] } \\
\text { 1964, pp. 25-849- } \\
\text { 850) }\end{array}$ \\
\hline $\begin{array}{l}\text { fugi-fugi [red. } \\
\text { completa] }\end{array}$ & $<\mathrm{i} .=$ 'joder' & & $\begin{array}{l}\text { (Perl, 1988, pp. } \\
61-63)\end{array}$ \\
\hline $\begin{array}{l}\text { guari-guari [red. } \\
\text { completa] }\end{array}$ & $\begin{array}{l}<\text { hb. }=\text { 'hablar o } \\
\text { charlar' }\end{array}$ & $\begin{array}{l}<\text { kik. wàdi= 'es, solo esta forma, } \\
\text { se usa tal que independientemente } \\
\text { en dialectos como wena }(=\text { widi) } \\
\text { para expresar la repetición de un } \\
\text { acto'; < kik. kāmu-kamu, kāu-kau, } \\
=\text { 'onomat. para una forma de } \\
\text { hablar'; < kik. lèko-leko = 'hablar } \\
\text { todo bajo [susurro]' [tener presente } \\
\text { el cambio /r/ }>\text { [d] explicado wàr } \\
=\text { wàdi] }\end{array}$ & $\begin{array}{l}\text { (Perl, 1988, pp. } \\
\text { 51-60-63); (Laman, } \\
\text { [1936] 1964, pp. } \\
\text { 210-389-1089) }\end{array}$ \\
\hline
\end{tabular}




\begin{tabular}{llll}
\hline $\begin{array}{l}\text { llari-llari [red. } \\
\text { completa] }\end{array}$ & $\begin{array}{l}<\mathrm{hb} .=\text { 'llorar o estar } \\
\text { triste o enfermo o } \\
\text { padecer algún dolor' }\end{array}$ & (Perl, 1988) \\
$\begin{array}{l}\text { luku-luku [red. } \\
\text { completa] }\end{array}$ & $<\mathrm{i} .=$ 'ver' & $\begin{array}{l}<\text { kik. yêlo-yelo= 'actitud que (Perl, 1988); } \\
\text { consiste en mirar alrededor, en (Laman, [1936] } \\
\text { todas las direcciones, seguir los 1964, pp. 1123- } \\
\text { ojos, cuidar'; < kik. yēdi-yedi = 1125) } \\
\text { 'perspicaz' }\end{array}$
\end{tabular}

\begin{tabular}{|c|c|c|c|}
\hline $\begin{array}{l}\text { fon-fon [red. } \\
\text { completa] }\end{array}$ & $\begin{array}{l}<\text { hb. }=\text { 'el castigo de } \\
\text { azotes' }\end{array}$ & & (Perl, 1988) \\
\hline $\begin{array}{l}\text { puru-puru [red. } \\
\text { completa] }\end{array}$ & $\begin{array}{l}\text { etimología no } \\
\text { clara posiblemente } \\
\text { 'exonerar el vientre' }\end{array}$ & & (Perl, 1988) \\
\hline meri-meri & $<\mathrm{hb}_{.}=$'borracho' & $\begin{array}{l}<\text { kik. vwāvala, vwāvalala = } \\
\text { 'borracho'; }<\text { kik. zùdi-zudi, } \\
\text { züdiba-zudiba }=\text { 'borracho de } \\
\text { alegría' }\end{array}$ & $\begin{array}{l}\text { (Perl, 1988, p. 52); } \\
\text { (Laman, [1936] } \\
\text { 1964, pp. 1039- } \\
\text { 1174) }\end{array}$ \\
\hline $\begin{array}{l}\text { bititi (ngó) [red. } \\
\text { parcial] }\end{array}$ & $\begin{array}{l}<1 \mathrm{p} .=\text { 'mirar, ver, } \\
\text { venir/ir a ver'; < pal. } \\
\text { bititi 'hierba'; < lp. = } \\
\text { 'pasta de yuca para } \\
\text { hacer almidón' }\end{array}$ & $<$ kik. bi-tíiti = 'hierbas' & $\begin{array}{l}\text { (Schwegler y } \\
\text { Rojas-Primus, } \\
\text { 2010, pp. 219); } \\
\text { (Laman, [1936] } \\
\text { 1964, pp. 34) }\end{array}$ \\
\hline $\begin{array}{l}\text { cheche } \\
\text { bacheche [red. } \\
\text { completa] }\end{array}$ & $\begin{array}{l}<\text { lp. = 'en buen } \\
\text { estado, de buena } \\
\text { salud, saludable, que } \\
\text { tiene mucha energía, } \\
\text { etc.'; < pal. bacheche } \\
=\text { 'listo para trabajar, } \\
\text { estar en forma' }\end{array}$ & $\begin{array}{l}<\text { kik. } k \overline{\mathrm{e}}-k \overline{\mathrm{e}}=\text { 'fuerte, sano'; } \\
k y \overline{\mathrm{e}} k y e, \text { donde se refiere a la } \\
\text { variante fonética } k \overline{\mathrm{e}}-k \overline{\mathrm{e}} ;<\text { kik. } b \bar{a} \\
=\text { 'estar' }+<\text { kik. } k \overline{\mathrm{e}}-k \overline{\mathrm{e}} ' ;<\text { kik. } b \overline{\mathrm{a}} \\
\text { es sinónimo de }<\text { kik. wà 'es/está' }\end{array}$ & $\begin{array}{l}\text { (Schwegler y } \\
\text { Rojas-Primus, } \\
\text { 2010, pp. 219- } \\
\text { 225-226); (Laman, } \\
\text { [1936] 1964, pp. } \\
\text { 5-225-367-1089) }\end{array}$ \\
\hline $\begin{array}{l}\text { ensusu [red. } \\
\text { parcial] }\end{array}$ & $\begin{array}{l}<\text { lp. ensuso, susu = } \\
\text { 'pollo, gallo, gallina, } \\
\text { ave doméstica' }\end{array}$ & $\begin{array}{l}<\text { kik. mu-sweswe = 'pollo'; < } \\
\text { kik. = kitsusu ='pollito'; < kik. } \\
\text { dyansusu = 'pollo, chica, chico'. }\end{array}$ & $\begin{array}{l}\text { (Gómez, 2010, } \\
\text { p. 72); (Laman, } \\
{[1936] \text { 1964, pp. }} \\
\text { 626-844-1053) }\end{array}$ \\
\hline $\begin{array}{l}\text { entoto [red. } \\
\text { parcial] }\end{array}$ & $\begin{array}{l}<\text { lp. }=\text { 'tierra, } \\
\text { cementerio' }<\text { pal. } \\
\text { entotocheche }= \\
\text { 'pueblo grande' }\end{array}$ & $\begin{array}{l}<\text { kik. ntó = 'borde (de bosque) } \\
\text { donde se entierra; cementerio' }\end{array}$ & $\begin{array}{l}\text { (Gómez, 2010, } \\
\text { p. 73); (Laman, } \\
{[1936] \text { 1964, p. }} \\
796)\end{array}$ \\
\hline $\begin{array}{l}\text { koko [red. } \\
\text { completa] }\end{array}$ & $\begin{array}{l}<\text { lp. = 'gallo'; acocó } \\
=\text { 'gallo' }\end{array}$ & $<$ kik. $k \bar{o} k o l o=$ 'el gallo canta' & $\begin{array}{l}\text { (Gómez, 2010, } \\
\text { p. 75); (Laman, } \\
{[1936] \text { 1964, p. }} \\
\text { 412) }\end{array}$ \\
\hline
\end{tabular}




\begin{tabular}{|c|c|c|c|}
\hline $\begin{array}{l}\text { kokódi [red. } \\
\text { parcial] }\end{array}$ & $\begin{array}{l}<\mathrm{lp} .=\text { 'gallo'; < lp. } \\
\text { enquico acheche = } \\
\text { 'gallo' }\end{array}$ & $<$ kik. $k \bar{o} k o l o=$ 'el gallo canta' & $\begin{array}{l}\text { (Gómez, 2010, } \\
\text { p. 75); (Laman, } \\
{[1936] \text { 1964, p. }} \\
412)\end{array}$ \\
\hline $\begin{array}{l}\text { meme [red. } \\
\text { completa] }\end{array}$ & $\begin{array}{l}<\mathrm{lp} .=\text { 'chivo, } \\
\text { carnero'; < lp. } \\
\text { memengó = 'carnero' }\end{array}$ & $\begin{array}{l}<\text { kik. mēme-meme = 'ovejas } \\
\text { jóvenes, cordero'; mēeme < kik. } \\
\text { mēeme = 'ovejas'; < kik. ma- } \\
\text { ntàba }=\text { 'cabra'; < kik. mà-mfuki= } \\
\text { 'cabra'; ma-nsùdi = 'cabra'; < kik. } \\
\text { meme-meme = 'un cordero' }\end{array}$ & $\begin{array}{l}\text { (Gómez, 2010, } \\
\text { p. 84); (Laman, } \\
\text { [1936] 1964, pp. } \\
\text { 491-498-499-548); } \\
\text { (Bentley, 1895, p. } \\
\text { 871) }\end{array}$ \\
\hline $\begin{array}{l}\text { tata [red. } \\
\text { completa] }\end{array}$ & $\begin{array}{l}<\text { lp. }=\text { 'forma } \\
\text { respetuosa de } \\
\text { dirigirse a los } \\
\text { ancianos' }\end{array}$ & $\begin{array}{l}<\text { kik. età, etata = 'sirve para } \\
\text { marcar un gran respeto'; tufyaukidi } \\
\text { eta = 'te agradecemos mucho } \\
\text { (nuestra gracia, tu grandeza)'; < } \\
\text { kik. kāakatà }<=\text { 'anciano'; < kik. } \\
\text { ese, tata = 'El uso de ese y tata, } \\
\text { es lo mismo que padre y papá en } \\
\text { inglés, e tata! padre!' }\end{array}$ & $\begin{array}{l}\text { (Gómez, 2010, } \\
\text { p. 95); (Laman, } \\
\text { [1936] 1964, pp. } \\
\text { 146-202); (Bentley, } \\
\text { 1895, p. 829) }\end{array}$ \\
\hline $\begin{array}{l}\text { yaya [red. } \\
\text { completa] }\end{array}$ & $\begin{array}{l}<\mathrm{lp} .=\text { 'madre'; } \\
\text { yayaendoqui }= \\
\text { 'madre de brujo' }\end{array}$ & $\begin{array}{l}<\text { kik. yàaya = 'madre, madre, } \\
\text { padre, suegro, abuela (madre } \\
\text { paterna). A partir de ahí, la palabra } \\
\text { yaaya se usa como título respetuoso } \\
\text { o denominación dirigida a una } \\
\text { persona (generalmente a mujeres) } \\
\text { a la que se desea honrar' }\end{array}$ & $\begin{array}{l}\text { (Gómez, 2010, } \\
\text { p. 96); (Laman, } \\
\text { [1936] 1964, p. } \\
\text { 1121) }\end{array}$ \\
\hline $\begin{array}{l}\text { quiquí [red. } \\
\text { completa] }\end{array}$ & < lp. 'arroz' & & $\begin{array}{l}\text { (Gómez, 2010, p. } \\
\text { 114) }\end{array}$ \\
\hline
\end{tabular}

Tabla 3. Reduplicaciones afrohispánicas encontradas y sus estructuras

Bentley (1895) indicó que para el kikongo algunos fenómenos como la pluralización y la estructuración de diminutivos se construyen a través del prefijo nominal $f$ - que denota cambio de tamaño, los diminutivos en la clase 7 se expresan en forma de duplicación, pero en la clase 8 la reduplicación indica pluralidad. Esta argumentación muestra que la reduplicación cumple un papel característico en la pluralización y la estructuración de diminutivos, lo cual repercute a nivel fonológico y morfológico. Una de las características de la reduplicación es su mayor aparición en criollos y pidgins que en el español estándar, quizá un posible aporte bantú a las lenguas afrohispanoamericanas. ${ }^{8}$ Un fenómeno particular se presenta en algunas

8 Concordamos con Perl (1988) cuando explica que se debe tener claro que aunque los criollos y pidgins manifiestan la reduplicación en sus estructuras y es una característica sobresaliente, no es una característica sustantiva de tales lectos. 
reduplicaciones palenqueras donde Schwegler (2000) encontró un gran número de este tipo de estructuras y considera que algunos lexemas derivados del español asumieron estructuras africanizadas modeladas por reduplicaciones derivadas. Por ejemplo, abraka-abraka, suebbe-suebbe (Schwegler, 1990, pp. 32-36).

A nivel formal, podemos decir que las reduplicaciones bozales son menos complejas que las reduplicaciones kikongo, aunque éstas encuentran gran similitud con las de la lengua palera. Si consideramos los niveles de complejidad de estas formas, el kikongo demuestra una complejidad mucho más alta, y pueden tener un significado distributivo o intensivo. ${ }^{9}$ La complejidad de estas realizaciones se demarca a través de la clase de iteración; 1) iteración básica (por ejemplo, cucha-cucha [red. completa] $<$ hb. cucha [verbo propiedad de la base] = 'escuchar'); y 2) iteración compleja (por ejemplo, musenga-musenga [red. completa] $<$ hb. = 'caña, caña', < kik. cēnga (Laman, [1936] 1964, p. 101) [sustantivo propiedad de la base] = 'caña de azúcar', en kikongo ти es prefijo singular de la clase 2.)

Gooden (2003, p. 33) identifica sobre la generalidad de las reduplicaciones léxicas, lo siguiente: «Las formas de entrada son sustantivos, verbos [adverbios] o adjetivos, pero la forma de salida es siempre un adjetivo.» En el caso de los sustantivos notamos, además, que los significados figurativos complican aún más su etimología y manejan cierto grado de impredecibilidad, otro aspecto en contra de la iconicidad.

\begin{tabular}{|c|c|c|c|c|c|c|}
\hline Clase & $\begin{array}{c}\text { Prefijo } \\
\text { nominal }\end{array}$ & $\begin{array}{c}\text { Característica de } \\
\text { la clase }\end{array}$ & Pronombres & Ejemplo & Glosa & $\begin{array}{c}\text { Acuerdos } \\
\text { nominales }\end{array}$ \\
\hline 1 & $\begin{array}{l}\text { mu-, mw-, } \\
\text { ḿ-, ̀̀-, }\end{array}$ & $\begin{array}{l}\text { Singular de la } \\
\text { clase } 2 \text { personas }\end{array}$ & $\mathrm{u}-$, & Muntu & Persona & Wa \\
\hline 2 & ba-, & $\begin{array}{l}\text { Plural de la clase } \\
1\end{array}$ & ba-, & Atu & Gente & A \\
\hline 3 & $\begin{array}{l}\text { mu-, mw, } \\
\text { ḿ-, ’̀̀-, }\end{array}$ & $\begin{array}{l}\text { Singular de la } \\
\text { clase } 4\end{array}$ & u-, & $\begin{array}{l}\text { mwinda/ } \\
\text { munsambu }\end{array}$ & $\begin{array}{l}\text { L á m p a r a / } \\
\text { pescado seco }\end{array}$ & wa \\
\hline 4 & $\begin{array}{l}\text { mi-, } \quad \text { my, } \\
\text { ḿ-, ǹ-, }\end{array}$ & $\begin{array}{l}\text { Plural de la clase } \\
3\end{array}$ & mi-, & $\begin{array}{l}\text { mi inda/ } \\
\text { minsambu }\end{array}$ & $\begin{array}{l}\text { Lámparas / } \\
\text { peces secos }\end{array}$ & mya \\
\hline 5 & di-, dy-, & $\begin{array}{l}\text { Singular de la } \\
\text { clase } 6\end{array}$ & di-, & dinkondo/se & Banana/padre & dya \\
\hline
\end{tabular}

9 Debido a que este enfoque no es muy claro, ya que se basa en los niveles de significado no se considera esta diferenciación en este espacio. La interpretación semántica de las palabras se realiza a partir de sus bases de producción, bases que tienen usos estrictamente léxicos. Así, los diferentes significados serían iterativos, intensivos, característicos, distributivos, atenuativos, estativos, entre otros (Gooden, 2003). 


\begin{tabular}{|c|c|c|c|c|c|c|}
\hline 6 & ma- & $\begin{array}{l}\text { Plural de la clase } \\
5, \quad 11, \quad 14, \quad 15 \\
\text { plural solamente }\end{array}$ & ma-, & $\begin{array}{l}\text { ma a z a / } \\
\text { mankondo/ } \\
\text { mase }\end{array}$ & $\begin{array}{l}\text { p lát a n o s / } \\
\text { padres }\end{array}$ & $\mathrm{ma}$ \\
\hline 7 & ki-, ky-, & $\begin{array}{l}\text { Singular de } \\
\text { la clase } 8, \\
\text { diminutivos, } \\
\text { instrumentos. }\end{array}$ & ki-, & kima/fulu & Cosa/lugar & kya \\
\hline 8 & bi-, by- & $\begin{array}{l}\text { Plural de la clase } \\
7,11,19 \text {, }\end{array}$ & bi-, & ima/fulu & $\begin{array}{l}\mathrm{C} \text { o s a s / } \\
\text { lugares }\end{array}$ & ya \\
\hline 9 & ny-, n-, m-, & $\begin{array}{l}\text { Singular de la } \\
\text { clase } 10 \text {, animales }\end{array}$ & yi-, & nkombo/nzo & Cabra/casa & wa/ya \\
\hline 10 & ny-, n-, m-, & $\begin{array}{l}\text { Plural de la clase } \\
9,11\end{array}$ & zi-, & $\begin{array}{l}\text { nsoni/nzo/ } \\
\text { nkombo }\end{array}$ & $\begin{array}{l}\mathrm{T} \text { i m i d e z / } \\
\text { casas }\end{array}$ & $\mathrm{za}$ \\
\hline 11 & lu-, lw-, & $\begin{array}{l}\text { Singular de la } \\
\text { clase } 6,8,10,12\end{array}$ & lu-, & Luumbu & Recinto & lwa \\
\hline 12 & tu-, tw-, & $\begin{array}{l}\text { Plural de la clase } \\
11\end{array}$ & tu- & Tuumbu & Recintos & twa \\
\hline 13 & $\mathrm{u}-$ & $\begin{array}{l}\mathrm{N} \text { o } \mathrm{m} \text { b } \mathrm{r} \text { e s } \\
\text { abstractos }\end{array}$ & & Unkete & aseo & wa \\
\hline 14 & bu-, bw-, & $\begin{array}{llll}\text { N o m b } & \text { r } & \text { e } \\
\text { abstractos } & & y \\
\text { singular de } & \text { la } \\
\text { clase } 6 & & & \end{array}$ & bu-, & & & \\
\hline 15 & ku-, kw-, & $\begin{array}{l}\text { In f i n i t i vos, } \\
\text { algunos nombres, } \\
\text { singular de la } \\
\text { clase } 6\end{array}$ & ku-, & $\begin{array}{l}\text { kwendal } \\
\text { kuulu }\end{array}$ & Ir/pie & kwa \\
\hline 16 & va-, & & oa-, & Vanzo & En casa & va \\
\hline 17 & ku-, & Alquiler & ku-, & Kuzandu & $\begin{array}{ll}\text { En } & \text { el } \\
\text { mercado }\end{array}$ & $\mathrm{ku}$ \\
\hline 18 & mu-, & & mu-, & Musuku & $\begin{array}{l}\text { En el } \\
\text { dormitorio }\end{array}$ & $\mathrm{mu}$ \\
\hline 19 & fi-, fy-, & $\begin{array}{lc}\text { Singular } & \text { de } \\
\text { la clase } & 8, \\
\text { diminutivos } & \end{array}$ & fi-. & Finuni & Un pajarito & fya \\
\hline 20 & & Falta & & & & \\
\hline
\end{tabular}

Tabla 4. Clases nominales kikongo y sus concordancias nominales

Fuente: Laman ([1936] 1964, p. LIII), y Fernando (2008, p. 13). 
Fernando (2008, pp. 12-13) considera, como se produce en otras lenguas bantúes, que los nombres en kikongo se clasifican en clases distinguidas por pares de prefijos, uno denota singularidad y el otro pluralidad. Además, los prefijos determinan el acuerdo verbal, el modificador y el acuerdo de cuantificación.

\begin{tabular}{|c|c|c|c|c|c|}
\hline $\begin{array}{c}\text { Pronombres } \\
\text { personales }\end{array}$ & Kikongo & Español & & Kikongo & Español \\
\hline $\begin{array}{l}1^{\text {ra }} \text { persona } \\
\text { singular }\end{array}$ & $-n-(-m-, \quad n-)$ & yo, mi, me & $1^{\text {ra }}$ persona plural & $t u$ - & $\begin{array}{l}\text { nosotros y nos, } \\
\text { nosotras y nos. }\end{array}$ \\
\hline $2^{\mathrm{da}}$ & -ku- (a menudo cae) & $t u ́, t i, t e$ & $2^{\mathrm{da}}$ & $l u-$ & $\begin{array}{l}\text { vosotros, } \\
\text { vosotras, vos y os }\end{array}$ \\
\hline $3^{\mathrm{da}}$ & $-m-(-n-, \check{n}-)$ & $\begin{array}{l}\text { él; ella, } \\
\text { ello; } \\
\text { le, la, lo }\end{array}$ & $3^{\text {ra }}$ & $a-$ & $\begin{array}{l}\text { ellos, ellas, les, } \\
\text { las, los }\end{array}$ \\
\hline
\end{tabular}

\section{Tabla 5. Prefijo de clase de sustantivos en kikongo}

Fuente: elaboración propia a partir de Fernando (2008, p. 14).

La tabla 5 ilustra los marcadores del objeto en kikongo, son prefijos para sustantivos que denotan seres humanos. Esta condición de la lengua kikongo se complementa con la característica de las palabras que por lo general terminan en vocales. Otro paralelismo morfológico expuesto con los ejemplos y etimologías de redundancias expuestas (ver tabla 3). La argumentación de Crowley (2008, p. 88) explica este criterio, «si bien las funciones de reduplicación bien pueden reflejar la iconicidad de la construcción, sus formas específicas pueden reflejar más directamente los patrones de sustrato específicos». Por otra parte, de manera general Lundström (1972, p. 58) considera que para comprender las reduplicaciones en esta lengua africana: «La característica del kikongo es el hecho de que todas las palabras y sílabas terminan con una vocal. Con la excepción de los sonidos nasales ( $n g, m b$, etc.) como regla, una consonante nunca debe estar junto con otra consonante». No obstante, Lundström advierte que existen excepciones como suele pasar en las diversas lenguas. Esto implica que cada sílaba finaliza con una vocal y las consonantes y las medias vocales se sitúan entre la siguiente vocal divididas en sílabas: «ja-nu-ali, enero; lu-mi-ngu lwa-lu-ne-ne, navidad» (Lundström, 1972, p. 58), divisiones que en el caso de las reduplicaciones afrohispanas observadas, se sitúan bisílabas como una constante coherente y paralela al kikongo. Por ejemplo; cu-cha-cu-cha, fi-no-fi-no, ti-fi-ti-fi, cha-pi-cha-pi, ña-mi-ña-mi. 


\section{Discusión y conclusiones}

Desde los primeros días del contacto interétnico de la trata esclavista en África se evidenciaron intercambios lingüísticos y, particularmente, reduplicaciones. En el siglo XVII términos como el portugués cada dia $<$ kik. = 'quilumbuyaquilumbu' (Bontinck y Nsasi, 1978, p. 50) empleaban reduplicaciones. Dos siglos más tarde, en el siglo XIX, Bantley (1895) identificó en el kikongo hablado por los bakongo reduplicaciones en numerales, modificaciones de sufijos, verbos, sustantivos partitivos, entre otros rasgos estructurales. De manera similar en el trabajo seminal de Laman ([1936] 1964) según constatamos figuran cerca de 175 reduplicaciones en kikongo. La argumentación de Schwegler (1990, p. 723) es sugestiva sobre este particular: «La formación de palabras mediante la reduplicación tiene un papel muy marginal en los idiomas europeos mientras que es muy importante en las lenguas bantúes», lo cual ratifica nuestra consideración de un presunto aporte kikongo a las hablas afrohispanoamericanas.

En el análisis llevado a cabo, no se encontraron reduplicaciones expletivas o de relleno, si consideramos que la función de las reduplicaciones obedece según su presunto sustrato kikongo a estructuras que indican patrones que pueden ser dependientes fonológicamente o por el contrario procesos léxicamente dependientes. En consecuencia, con lo anterior, consideramos que las reduplicaciones en las lenguas vernáculas afrohispanas indican una transferencia morfológica de una primigenia africana. En algunos términos las reduplicaciones se precisan completas (copia total) y en otras parciales (copia incompleta) aunque ambas modalidades conserven significados habituales, lo que indica procesos de continuidad y correspondencia, como se pudo comprobar en los ejemplos señalados.

De hecho, en varios casos, la transferencia directa de las lenguas africanas es fehaciente y comprobable — como se demostró en este espacio-, en menor medida las reduplicaciones podrían considerarse procesos de creación e innovación lexical y fonológica, debido a que la evidencia histórica y el contexto etnolingüístico no sostiene esta segunda consideración. Resta abordar los aspectos considerados en este espacio en los dialectos afroibéricos que son de interés para la dialectología afrolatinoamericana; el afroyungueño boliviano, el afroparaguayo, el afroperuano, el afrochileno, el venezolano de Barlovento, el afropuertorriqueño, el afromexicano, el chota ecuatoriano, el chocoano colombiano, el afrodominicano, el dialecto panameño de los congos y el vernacular brasileño. 


\section{Referencias bibliográficas}

1. Bentley, W.H. (1895). Dictionary and grammar of the Kongo language as spoken at San Salvador, the ancient capital of the old Kongo empire, West Africa. London: Baptist Missionary Society and Kegan Paul, Trench, Trübner \& Co.

2. Birmingham, D. (1999). Portugal and Africa. London: Macmillan Press.

3. Bontinck, F., y Nsasi, N. (1978). Le Catéchisme kikongo de 1624. Réedition critique. Bruxelas: Académie Royale des Sciences d'Outre-Mer.

4. Borja Medina, F.d. (2010). La experiencia sevillana de la Compañía de Jesús en la evangelización de los esclavos negros y su representación en América. En Martín Casares, A. y M. García, Barranco (comps.), La esclavitud negroafricana en la historia de España Siglos XVI y XVII (pp. 75-94.). Granada: Comares.

5. Bostoen, K. y de Schryver, G-M. (2015). Linguistic innovation, political centralization and economic integration in the Kongo kingdom: Reconstructing the spread of prefix reduction. Diachronica, 32(2), pp. 139-85.

6. Byrd, S. (2007). Calunga: uma fala afro-brasileira de Minas Gerais, sua gramática e história. Revista Internacional de Lingüistica Iberoamericana, 5 (9), pp. 203-222.

7. Byrd, S. (2012a). Calunga and the legacy of an African language in Brazil. Albuquerque: University of New Mexico Press.

8. Byrd, S. (2012b). The Afro-Brazilian Speech of Calunga: Historical, Sociolinguistic, And Linguistic Considerations. The Journal of Pan African Studies, 5(5), pp. 101-123.

9. Childs, T. (1994) African Ideophones. Hinton, Leane Nichols, Johanna y Ohala, John (1994). Sound Symbolism (pp. 178-204). Cambridge, New York, Melbourne: Cambridge University Press.

10. Correa, J.A. (2012). El español hablado en el pacífico de Colombia: dos rasgos fonéticos de presunto sustrato africano. En File-Muriel, R. y Orozco, R. (eds.), Colombian Varieties of Spanish (pp. 43-66). Madrid, Frankfurt: Iberoamericana, Vervuert.

11. Crowley, T. (2008). Pidgin and Creole Morphology. En S. Kouwenberg and J. V. Singler (eds.), The Handbook of Pidgin and Creole Studies (pp. 74-97). Oxford, UK.: Wiley-Blackwell.

12. Cuba, M.C. (1996). El castellano hablado en Chincha. Lima: Universidad Nacional Mayor de San Marcos, Escuela de Posgrado.

13. De Kind, J. (2012). Taalvariatie in het Kikongo van Angola vanuit historisch perspectief: fonologie en morfologie. Ghent: Universiteit Gent MA thesis.

14. De Kind, J., Dom, S., Schryver, G-M., Bostoen, K. (2012). Bantu Forensic Lexicography: a Kikongo case study.17th International Conference of the African Association for Lexicography, University of Pretoria, South Africa, 2-5 July 2012.

15. De Kind, J. Dom, S., Schryver, G-M., Bostoen, K. (2015). Event-centrality and the pragmaticssemantics interface in Kikongo: From predication focus to progressive aspect and vice versa. Folia Linguistica Historica, 36, pp. 113-163. En S. Dom y K. Bostoen (2015). Examining variation in the expression of tense/aspect to classify the Kikongo Language Cluste. Africana Linguistica, 21, pp. 163-211.

16. Domingues da Silva, D. (2017) The Atlantic Slave Trade from West Central Africa, 1780-1867. Slave Origins. Cambridge: Cambridge University Press. 
17. Dryer, M. (2009). Verb-object-negative order in Central Africa. En Cyffer, N., Ebermann, E., y Ziegelmeyer, G. (eds.), Negation Patterns in West Africa (pp. 307-362). Amsterdam: John Benjamins.

18. Fernando, M. (2008). An Analysis of Verbal Affixes in Kikongo With Special Reference to Form and Function. (Tesis de maestría), Pretoria, University of South Africa.

19. Fontanella de Weinberg, M.B. (1996). El aporte de la sociolingüística histórica al estudio del español. International Journal of the Sociology of Language, 117(1), pp. 27-38.

20. Fuentes-Guerra, J. y Schwegler, A. (2014). El origen kongo del Palo Monte: una aproximación etnolingüística. UniverSOS, 11, pp. 9-61.

21. Gil, D. (2005). From repetition to reduplication in Riau Indonesian. En B. Hurch, V. Mattes (eds.), Studies on Reduplication (pp. 31-64). Berlín: Mouton de Gruyter.

22. Gómez Mejías, L. (2010). Remanentes de lenguas bantúes en la ciudad de Ciego de Ávila. (Tesis de Pregrado, Licenciatura en Letras), Universidad Central "Marta Abreu" de Las Villas, Santa Clara, Cuba.

23. Gooden, B., Shelome A. (2003). The phonology and phonetics of Jamaican creole reduplication. (Tesis de doctorado), Ohio, The Ohio State University.

24. Granda, G. de. (1968). La tipología ‘criolla' de dos hablas del área lingüística hispánica. Thesaurus, 23 (2), pp. 193-205.

25. Granda, G. de. (1977). Estudios sobre un área dialectal hispanoamericana de población negra: las tierras bajas occidentales de Colombia. Bogotá: Instituto Caro y Cuervo.

26. Guthrie, M. (1967-1970). Comparative Bantu. 4vol. Farnborough, Hants: Gregg International Publishers.

27. Hilton, A. (1985). The Kingdom of Kongo. Oxford: Clarendon.

28. Jacobs, B. (2014). Commentary. El origen "kongo" del Palo Monte (Cuba): una aproximación etnolingüística de J. Fuentes Guerra/A. Schwegler. UniverSOS, 11, pp. 63-69.

29. Jadin, L. (1961). Le Congo et la secte des Antoniens : restauration du royaume sous Pedro IV et la "saint-Antoine" congolaise (1694-1718). Brussels: Institut historique belge de Rome.

30. Kouwenberg, S., y D. LaCharité (2001) The iconic interpretations of reduplication: Issues in the study of reduplication in Caribbean Creole languages. European Journal of English Studies, 5, pp. 59-80.

31. Laman, K.E. ([1936] 1964). Dictionnaire kikongo-français. 2 tomos. Ridgewood, NJ: The Gregg Press.

32. Likangama, M. (1990). Les emprunts linguistiques du kikongo au portugais.Taira 2, pp. 91-109.

33. Lipski, J.M. (1989). The speech of the NEGROS CONGOS of Panama. Amsterdam: John Benjamins.

34. Lipski, J.M. (2006). Logros recientes de la lingüística afrohispánica: implicaciones para las lenguas criollas y el español de América. ENDIL XXV (Encuentro Nacional de Investigadores y Docentes de Lingüística). Universidad del Zulia, Maracaibo, Venezuela, June 15, 2006.

35. Lipski, J.M. (2007). El cambio/R/> [D] en el habla afrohispánica: ¿Un rasgo fonético "Congo" ?, Boletín de lingüística, XIX (27), pp. 94-114.

36. Lundström, M. (1972). The problem of language in translating religious concepts into Kikongo. Ethnos: Journal of Anthropology, 37(1-4), pp. 53-80. 
37. Maho, J.F. (2006) The new updated Guthrie list. Homepage of Jouni Filip Maho. Recuperado de http://goto.glocalnet.net/maho/bantusurvey.html

38. Martins, M.d.M. (1958). Contribução para o estudo da influência do português na língua quicongo. Garcia de Orta, 6, pp. 33-51.

39. McWhorter, J.H. (2018). Why neither demographics nor feature pools can explain the missing Spanish plantation creoles Taxonomy: Morphology, sociocultural linguistics. Lingua: International review of general linguistics, 202, pp. 4-12.

40. Megenney, W. (1999). El español afrocaribeño: ¿mito o realidad?, EnLópez Ortiz (ed.), El Caribe hispánico: perspectivas lingüísticas actuales. Homenaje a Manuel Álvarez Nazario (pp. 271-294). Madrid-Frankfurt, Iberoamericana-Vervuert.

41. Miller, J.C. (1998). Way of Death: Merchant Capitalism and the Angolan Slave Trade, 1730-1830. Madison: University of Wisconsin Press.

41. Murillo Mena, M. (2011). Sentidos de formación de maestros y etnoeducadores en la universidad tecnológica del chocó -UTCH-Colombia. ARJÉ Revista de Postgrado FACE-UC., 5(8), pp. 27-47.

42. Núñez, R. (2014). Modelo autosegmental jerárquico. En R. Núñez, S. Colina, y T. Bradley, (eds.), Fonología generativa contemporánea de la lengua española (pp. 83-152). Washington, DC: Georgetown University Press.

43. Perl, M. (1988). Rasgos poscriollos léxicos en el lenguaje coloquial cubano. Criollística comparada. Thesaurus, 43(1), pp. 47-64.

44. Pigafetta, F. ([1591] 1978). Relazione del Reame di Congo Milan: Ed. Georgio Cardona.

45. Ruiz-García, M. (2001). El español popular de Chocó: evidencia de una reestructuración parcial. (Tesis de doctorado), University of New Mexico, New Mexico, Ann Arbor.

46. Santa Cruz, N. (1982). La décima en el Perú. Lima: Instituto de Estudios Peruanos.

47. Santos Morillo, A. (2015). Catequesis de negros y enseñanza del español en la Hispanoamérica colonial a la luz de las modernas teorías sobre adquisición de segundas lenguas. MarcoELE, 21, pp. 71-94.

48. Sandoval, A.d. ([1627] 1956). De instuaranda aethiopum satlute. Bogotá: Empresa Nacional de Publicaciones.

49. Schwegler, A. (1990). "Abrakabraka”, y "Suebbesuebbe" y otras voces palenqueras: sus orígenes e importancia para el estudio de dialectos afrocaribeños. Thesaurus, 45 (3), pp. 690-731.

50. Schwegler, A. (2000). The African vocabulary of Palenque (Colombia). Part 1: Introduction and corpus of previously undocumented Afro-Palenquerisms. Journal of Pidgin and Creole Language, 15, pp. 241-312.

51. Schwegler, A. (2016). Genética poblacional (ADN) y lingüística histórica: Sobre los orígenes africanos de la población de El Palenque de San Basilio (Colombia). En J. M. Santos Rovira (ed.), Centros de irradiación y periferias de la lengua española (pp. 23-48). Lugo: Axac.

52. Schwegler, A. (2018). On the controversial origins of non-canonical Spanish and Portuguese negation: case closed? Lingua: International review of general linguistics, 202, pp. 24-43.

53. Schwegler, A. y Rojas-Primus, C. (2010). La "lengua" ritual del Palo Monte (Cuba): estudio comparativo (Holguín / Cienfuegos). Revista Internacional de Lingüistica Iberoamericana (rili), 15, pp. 187-244.

54. Schwegler, A., McWhorter, J., y Ströbel, L. (eds.) (2016). The Iberian Challenge: Creole Languages Beyond the Plantation Setting. Frankfurt, Madrid: Vervuert, Iberoamericana. 
55. Sebba, M. (1981). Derivational Regularities in a Creole Lexicon: the case of Sranan. Linguistics, 19, pp. 101-117.

56. Sessarego, S. (2017). Chocó Spanish double negation and the genesis of the Afro-Hispanic dialects of the Americas. Diachronica, 34(2), pp. 219-252.

57. Smith, N. (2015). The early history of Surinam: Why is Surinam different? En P. Muysken y N. Smith (eds.), Surviving the Middle Passage (pp. 17-42). Berlin: Walter de Gruyter Mouton.

58. Swartenbroeckx, P.S.J. (1973). Dictionnaire kikongo et kituba-français (vocabulaire comparé des langages kongo traditionnels et véhiculaires). Bandundu: CEEBA Publications.

59. Thornton, J. (1998). Africa and Africans in the Making of the Atlantic World, 1400-1800. Cambridge: Cambridge University press.

60. Van Gheel, J. (1652). Vocabularium Latinum, Hispanicum, e Congense. Manuscript kept in the National Central Library of Rome: Fundo Minori 1896, MS Varia 274.

61. Van Wing, J. y Penders. C. (1928). Le plus ancien dictionnaire bantu / Het oudste Bantuwoordenboek. Vocabularium P. Georgii Gelensis. Louvain: J. Kuyl-Otto.

62. Vansina, J. (1962). Long-distance trade routes in Central Africa. Journal of African History, 3(3), pp. 375-390.

63. Zwartjes, O. (2011). Portuguese Missionary Grammars in Asia, Africa and Brazil, 1550- 1800. Amsterdam: John Benjamins Publishing Company. 